\title{
Long-term neurodevelopmental outcomes in school-aged children after neonatal arterial switch operation
}

Hedwig H. Hövels-Gürich, $\mathrm{MD}^{\mathrm{a}}$

Marie-Christine Seghaye, MD ${ }^{a}$

Ralph Schnitker, MA ${ }^{\mathrm{b}}$

Magdalene Wiesner ${ }^{\mathrm{a}}$

Walter Huber, $\mathrm{PhD}^{\mathrm{b}}$

Ralf Minkenberg ${ }^{\mathrm{c}}$

Franz Kotlarek, MD ${ }^{\mathrm{d}}$

Bruno J. Messmer, $\mathrm{MD}^{\mathrm{e}}$

Götz von Bernuth, MD

See related editorial on page 425
Objective: Neurodevelopmental status of children between 8 and 14 years of age after neonatal arterial switch operation for transposition of the great arteries has not previously been systematically evaluated.

Methods: Within a longitudinal study, 60 unselected children operated on as neonates with combined deep hypothermic circulatory arrest and low-flow cardiopulmonary bypass were reevaluated at the age of 7.9 to 14.3 years (mean $\pm \mathrm{SD}$ $10.5 \pm 1.6$ years). Clinical neurologic status and standardized tests to assess gross motor function, intelligence, acquired abilities, language, and speech were carried out, and the results were related to preoperative, perioperative, and postoperative status, to management, and to neurodevelopmental status at a mean age of 5.4 years.

Results: Neurologic and speech impairments were evidently more frequent (27\% and $40 \%$, respectively) than in the general population. Intelligence and socioeconomic status were not different $(P=.29$ and $P=.11)$, whereas motor function, acquired abilities, and language were reduced ( $P \leq .04$ for each). Overall rate of developmental impairment in one or more domains was 55\%, compared with $26 \%$ at age 5.4 years. Multivariable analysis showed that severe preoperative acidosis and hypoxia predicted reduced motor function (mean deficit 52.7 points, $P<.001$ ), whereas longer bypass duration predicted both neurologic (odds ratio per 10 minutes of bypass duration 1.8, $P=.04$ ) and speech (odds ratio per 10 minutes of bypass duration 1.9, $P=.02$ ) dysfunction, and perioperative and postoperative cardiocirculatory insufficiency predicted neurologic (odds ratio $6.5, P=.04$ ) and motor (mean deficit 6.8 points, $P=.03$ ) dysfunction.

Conclusions: The neonatal arterial switch operation with combined circulatory arrest and low-flow bypass is associated increasingly with age, with reduced neurodevelopmental outcome but not with cognitive dysfunction. In our experience, the risk of long-term neurodevelopmental impairment after neonatal corrective cardiac surgery is related to deleterious effects of the global perioperative management and to special adverse effects of prolonged bypass duration. Severe preoperative acidosis and hypoxia and postoperative hemodynamic instability must be considered as important additional risk factors. 


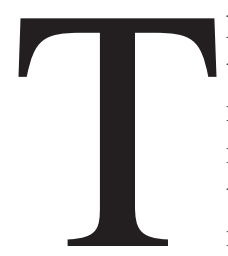

he arterial switch operation (ASO) to correct transposition of the great arteries (TGA) in neonates has been globally accepted as the method of choice because of low perioperative and postoperative mortality and good midterm results with respect to the cardiologic outcomes and endurance of these children. Concern, however, has been raised by the occurrence of neurologic dysfunction and developmental sequelae that may accompany neonatal cardiac surgery supported by continuous lowflow cardiopulmonary bypass (CPB), either isolated or combined with deep hypothermic cardiocirculatory arrest (DHCA).

Previously, we reported midterm results of cognitive and motor development in preschool- and school-aged children at a mean age of 5.4 years after neonatal ASO performed between 1986 and 1992 with combined DHCA and lowflow CPB. ${ }^{1}$ Our patient group had reductions in neurologic and fine and gross motor functions, vocabulary, and acquired abilities, but was within the reference range for formal intelligence testing. In contrast, a second group of children who had undergone ASO between 1994 and 1995 and were assessed in our institution at a mean age of 3.6 years revealed remarkably less developmental impairment than seen in our older children. ${ }^{2}$ Midterm results of the Boston Circulatory Arrest Study at the age of 4 years after neonatal $\mathrm{ASO}^{3}$ demonstrated reduced performance of the full cohort with respect to several domains of testing, including neurologic and motor functions, intelligence, and language. Use of circulatory arrest was associated with worse outcomes in motor and speech functions than seen with the preponderant use of low-flow CPB. Recent results of a developmental evaluation of children aged 3 to 5 years after corrective infant cardiac surgery, including patients after neonatal ASO, add to the evidence of risks concerning neurologic and cognitive function but do not support the assumption of increased risk using cardiac arrest. ${ }^{4}$

Limited conclusions can be drawn from these findings with respect to the impact of the different bypass strategies and their concomitant modalities and the impact of preoperative and postoperative risk parameters on final developmental status after neonatal corrective cardiac surgery. The aim of this study was therefore to evaluate for the first time long-term neurologic, motor, cognitive, academic, language, and speech development 10 years after ASO by reassessment of our uniform group of children with TGA. ${ }^{1}$ Further information should be obtained as to which factors in preoperative, perioperative, and postoperative management influence long-term outcome and to what degree neonatal surgery performed with DHCA and with CPB by itself may contribute to neurologic and developmental impairment in older school-aged children and adolescents.

\section{Methods}

\section{Patient population}

Between March 1986 and February 1992, 96 neonates with TGA underwent ASO. In 1995, at a mean age of 5.4 years, 77 children ( $86.5 \%$ of the survivors) were evaluated with respect to their cognitive and motor development. ${ }^{1}$ In 2000, at a mean ( \pm SD) age of $10.5 \pm 1.6$ years (range 7.9-14.3 years), 60 of them were reevaluated. The remaining 17 patients were evaluated with a questionnaire. There were no further late deaths. All patients, except those with cerebral palsy, had normal endurance capacity, and none received any cardiac-related medication.

Our study was approved by the ethical medical committee of the Aachen University of Technology, Aachen, Germany, and written informed consent was obtained from the patients and their parents. The study comprised a longitudinal comparison with our former evaluation ${ }^{1}$ and was designed as a case series with published controls and prognostic factor analyses. The study group consisted of 60 unselected children (77.9\% of the survivors), 46 $(76.7 \%)$ of whom were male and $14(23.3 \%)$ of whom were female. Socioeconomic status of the families ${ }^{5}$ was not different from that of a general population $\left(P=0.11, \chi^{2}\right.$ test). Seventy-three percent had a simple TGA, $17 \%$ in addition had an unimportant ventricular septal defect, $3 \%$ had a ventricular septal defect closed during ASO, and 7\% had a coarctation of the aorta corrected later. Eighty-five percent of the neonates had undergone atrial balloon septostomy, and all had been treated with prostaglandin $\mathrm{E}_{1}$ before the operation.

Questionnaires for the 17 patients who did not participate in the present follow-up study were completed by the parents and by the treating pediatricians and pediatric cardiologists; participation was determined mainly by the distance of the family's residence from our institution. The children who did not participate in the study were not different from the study patients with respect to socioeconomic background.

\section{Surgical Management and Perfusion Methods}

ASO under conditions of DHCA and combined low-flow CPB was performed in our institution by two surgeons (B. J. Messmer, S. H. Daebritz) according to a standardized technique that was based on the Lecompte modification. The CPB circuit included a roller pump, a disposable membrane oxygenator, and an arterial filter. Cooling and rewarming were carried out with a heat exchanger. After induction of general anesthesia, core cooling on CPB was instituted under full-flow conditions $\left(2.7 \mathrm{~L} /\left[\mathrm{m}^{2}\right.\right.$ body surface area - min]) to reach an esophageal temperature of $14^{\circ} \mathrm{C}$ to $17^{\circ} \mathrm{C}$ $\left(15.1^{\circ} \mathrm{C} \pm 1.0^{\circ} \mathrm{C}\right)$. The temperature of the priming fluid was $20^{\circ} \mathrm{C}$ to $22^{\circ} \mathrm{C}$. The priming solution consisted of a pH-balanced crystalloid solution containing 5\% glucose and packed red blood cells to achieve a hematocrit value of the circulating volume of 0.25 . The duration of core cooling ranged from 7 to 20 minutes $(10.8 \pm 2.7$ minutes). Duration of DHCA ranged from 51 to 67 minutes $(60.0 \pm 3.1$ minutes $)$, and the aortic crossclamping period ranged from 53 to 96 minutes $(65.7 \pm 8.1$ minutes). The surgical procedure was completed under low-flow conditions with a perfusion rate of $0.7 \mathrm{~L} /\left(\mathrm{m}^{2}\right.$ body surface area $\left.\cdot \min \right)$. Rewarming and preparation for weaning from $\mathrm{CPB}$ were achieved under full-flow conditions. Total $\mathrm{CPB}$, including core rewarming time, comprised 42 to 98 minutes $(63.4 \pm 13.7$ minutes $)$. During $\mathrm{CPB}$ the $\mathrm{pH}$-stat 
TABLE 1. Preoperative, perioperative, and postoperative courses: risk factors for neurodevelopmental outcome

\begin{tabular}{lr}
\hline Risk factor & Result \\
\hline Perinatal asphyxia (No.) & $8 / 60(13.3 \%)$ \\
Severe preoperative acidosis and hypoxia (No.) & $7 / 60(11.7 \%)$
\end{tabular}

Definition

Severe preoperative acidosis and hypoxia (No.)

$7.1 \pm 5.1$

$60.0 \pm 3.1$

$63.4 \pm 13.7$

$65.7 \pm 8.1$

$10.8 \pm 2.7$

$15.1 \pm 1.0$

$2 / 60(3.3 \%)$

$10 / 60(16.7 \%)$

Perioperative and postoperative cardiocirculatory insufficiency (No.)

Perioperative and postoperative resuscitation events (No.) $\quad 4 / 60(6.7 \%)$

Postoperative intraventricular cerebral hemorrhage (No.) $\quad 4 / 60(6.7 \%)$

Perioperative and postoperative clinical seizures (No.)

Age at neurodevelopmental testing $(y$, mean \pm SD)

Socioeconomic status
$2 / 60(3.3 \%)$

$10.5 \pm 1.6$

$P=.11 \dagger$ vs published control values
Apgar score $<7$ after 5 min

$\mathrm{pH}$ value $<7.2$ in umbilical venous blood ( $\mathrm{n}$ $=3$ ); severe postasphyxia syndrome with organ failure and cerebral seizures $(\mathrm{n}=$ 2); repeated severe cyanosis caused by intracardiac mixing problems $(n=2)$

Low cardiac output* despite adequate filling pressures and inotropic and vasodilatory therapy

Pharmacologic or mechanical resuscitation necessary

Evaluation by cranial ultrasonography before operation; 4 h after operation; 1, 2, and $3 \mathrm{~d}$ after operation; and 1 and 2 wk after operation; persistence of intraventricular cerebral hemorrhage-like findings 2 weeks after operation, according to Sigler et al ${ }^{6}$

Social classification of family by main breadwinner's profession, according to Moore and Kleining ${ }^{5}$

*Low cardiac output was clinically estimated by means of arterial pressure (target value for mean pressure $45 \mathrm{~mm} \mathrm{Hg}$ ), central venous pressure (target value $5-7 \mathrm{~mm} \mathrm{Hg}$ ), diuresis (target value $>1.5 \mathrm{~mL}$ [ $[\mathrm{kg}$ body weight $\cdot h]$ ), capillary refill time, and skin temperature.

$\dagger P$ value calculated by comparison of frequencies; socioeconomic status represents an ordinal scale.

method was used, correcting arterial carbon dioxide tension $\left(\mathrm{PacO}_{2}\right)$ to the patient's hypothermic temperature to maintain a $\mathrm{pH}$ value of 7.40. At the beginning of CPB, phentolamine $(0.1 \mathrm{mg} / \mathrm{kg})$ and (since 1990) sodium nitroprusside were added for vasodilatation. Dexamethasone $\left(3 \mathrm{mg} / \mathrm{m}^{2}\right.$ body surface area) was given before sternotomy. The age at repair for the study group ranged from 2 to 39 days $(7.1 \pm 5.1$ days). Two patients were older than 12 days.

\section{Risk Factors for Neurodevelopmental Outcome}

The patients' charts were carefully reviewed with respect to perioperative management and preoperative, perioperative, and postoperative complications. For the analysis of the influence of cerebral risk factors on later outcome, a list of 15 definite variables, available in all cases, was considered (Table 1). ${ }^{6}$

\section{Neurologic Examination}

Complete clinical neurologic status was evaluated by an examiner experienced in neuropediatric examinations (H. H. Hövels-Gürich). Results were classified as normal or impaired. Impairment was categorized as mild (no functional impairment), moderate (functional impairment requiring therapy), or severe (dependence on continued assistance). Disorders were subclassified into 7 types of dysfunction (more than one of which could be present in a single case) as follows: disorders of either head shape and growth or cranial nerves, motor dyspraxia, ataxia, sensory dysfunction, palsy, and seizures (clinical or electroencephalographic) during the last 12 months $^{7-9}$ (Table 2). Isolated nonparalytic strabismus was not classified as neurologic disorder and was excluded from further analysis in this setting.

\section{Developmental Testing}

All assessments were conducted in the whole cohort by the same examiner during the morning hours in our institution. The applied tests are normalized for age to have a mean $( \pm$ SD) of $100 \pm 15$. Dysfunction was diagnosed when standard scores were below the simple SD (standard scores $<85$ ).

The Kiphard and Schilling Body Coordination Test ${ }^{10}$ was administered to assess standard scores of gross motor function (motor quotient, MQ).

The Kaufman Assessment Battery for Children ${ }^{11}$ was performed to evaluate overall standard score of general intelligence (IQ). A second test block of the same battery was undertaken to evaluate acquired abilities (learning, academic knowledge). Three 
patients (5\%) who were older than 12.5 years were assessed according to the norms for children aged 12.0 to 12.5 years.

Language was assessed by evaluating standard scores of expressive (combination of chosen items comprising subtests 4, 12, 14, and 15 of the Kaufman Assessment Battery for Children) and receptive language (combination of chosen items comprising subtests 7, 13, 14, and 16 of the Kaufman Assessment Battery for Children)

Developmental test results in the patients were compared with the published results of an age-matched healthy, German-speaking population, on which the tests or their German adaptations are based. The incidence of abnormal results in a reference population is by definition $16 \%$ ( $14 \%$ below the simple SD but above the double SD and $2 \%$ below the double SD).

\section{Examination of Speech}

At the time of assessment, all children had normal hearing, as evaluated by tone threshold audiometry. Speech was assessed with the Oral and Speech Motor Control test ${ }^{12}$ and selected items of the children's battery of the Mayo Tests of Speech and Oral Apraxia, ${ }^{13}$ both adapted to the German language by our neurolinguists (W.H. and R.S.). In addition, we performed the German version of the Auditory Closure subtest of the Illinois Test of Psycholinguistic Abilities (ITPA), ${ }^{14}$ as well as the Test of Auditory Analysis Skills ${ }^{15}$ in a German adaptation (W.H. and R.S.), both of which assess auditory comprehension and phonation. Patients were classified as having a normal or an impaired overall speech function according to the total functional score (TFS) ${ }^{12}$ comprising 56 items (maximum 112 points) with respect to function of volitional oral movements, articulation, phonation, and coordination of speech. The cutoff point for an impaired speech function was set at a score of less than 110 points, which is equivalent to the median value reported by Robbins and Klee. ${ }^{12}$ Reliability of this classification was verified by relating the additional speech assessments to the TFS.

\section{Statistical Analysis}

Results are expressed as mean \pm SD or as numbers with percentages. For comparison of mean values, $t$ tests were applied; for comparison of frequencies, the $\chi^{2}$ test was used. For intergroup comparison of clinical variables, the nonparametric Mann-Whitney $U$ test was applied. For comparison of variables at specific times of assessment within a group, the paired nonparametric Wilcoxon test was used. The Spearman rank correlation coefficient was assessed for correlation of independent parameters, and the Fisher exact test was used for the analysis of contingency tables. An $\alpha$ adjustment for repeated measures was done according to the Bonferroni-Holm method. To study the impact of risk factors on neurodevelopmental outcome parameters, a multivariable analysis was applied with a generalized linear model for continuous outcome parameters and a logistic regression model for binary outcome parameters with 8 independent risk factors, 4 of which were statistically significant in corresponding univariate analysis: severe preoperative hypoxia, durations of DHCA and CPB, perioperative and postoperative cardiocirculatory insufficiency, perioperative and postoperative resuscitation events, perioperative and postoperative clinical seizures, postoperative intraventricular cerebral hemorrhage, and socioeconomic status.
TABLE 2. Neurologic dysfunction after ASO, as evaluated in 60 children

\begin{tabular}{llc}
\hline & No. & $\%$ \\
\hline Total with dysfunction & 16 & 26.7 \\
\hline Grade of dysfunction & & \\
Mild & 9 & 15 \\
Moderate & 5 & 8.3 \\
Severe & 2 & 3.3 \\
\hline Type of dysfunction* & & \\
Head shape and & $5 \dagger$ & 8.3 \\
growth & & \\
Cranial nerves & $6 \ddagger$ & 10 \\
Motor dyspraxia & $8 \S$ & 13.3 \\
Ataxia & 5 & 0.3 \\
Sensory & 0 & 5 \\
Palsy & $3 \|$ & 5 \\
Seizures & 3 & \\
\hline
\end{tabular}

*More than one type of dysfunction possible in one child.

tMicrocephaly, $\mathrm{n}=3$; macrocephaly, $\mathrm{n}=1$; hydrocephalus with ventriculoperitoneal shunt, $\mathrm{n}=1$.

$\ddagger$ Dysfunction of palate or tongue, $n=5$; nystagmus, $n=1$.

$\S$ Developmental fine or gross motor coordination disorder.

\|Quadriplegia or hemiplegia.

Multivariate discrimination analysis was performed to test the discriminatory power of neurologic and speech functional scores with respect to combined dysfunctions in the domains of motor, cognitive, and academic abilities.

Statistical analysis was performed with the SPSS for Windows software, version 10.0 (SPSS GmbH Software, München, Germany), and with the Statistical Analysis System, version 8.0 (SAS Institute, Inc, Cary, NC). The term significant was used to indicate purely statistical, not clinical, significance.

\section{Results}

\section{Neurologic Status}

Sixteen children (26.7\%) had neurologic abnormalities, $56 \%$ of which were considered mild. Rates, grades, and types of dysfunctions are described in Table 2. Neurologic dysfunction was found to be associated with lower MQ $(P<.001)$ and IQ $(P=.001)$ and with poorer outcomes for acquired abilities $(P=.005)$ and receptive language $(P<$ $.001)$.

\section{Developmental Evaluation}

Gross motor dysfunction was found in $26.7 \%$ of the patients (11.7\% below the simple SD and $15 \%$ below the double SD for MQ). Reduced formal intelligence was diagnosed in $18.3 \%$ (15\% below the simple SD and $3.3 \%$ below the double SD for IQ), and dysfunction in academic knowledge (acquired abilities) was diagnosed in $23.3 \%$ (18.3\% below the simple SD and $5.0 \%$ below the double SD). Expressive language was found to be reduced in $18.3 \%$ (18.3\% below the simple SD) and receptive language was found to be 
TABLE 3A. Speech outcome after ASO: Distribution of TFS

\begin{tabular}{lrc}
\hline & \multicolumn{2}{c}{ Patients } \\
\cline { 2 - 3 } TFS & No. & $\%$ \\
\hline Normal & & \\
112 & 7 & 11.7 \\
111 & 13 & 21.7 \\
110 & 16 & 26.7 \\
Total & 36 & 60 \\
\hline Impaired & & \\
109 & 6 & 10 \\
108 & 4 & 6.7 \\
107 & 2 & 3.3 \\
106 & 1 & 1.7 \\
105 & 3 & 5 \\
104 & 1 & 1.7 \\
103 & 1 & 1.7 \\
96 & 2 & 3.3 \\
95 & 1 & 1.7 \\
91 & 1 & 1.7 \\
65 & 1 & 1.7 \\
54 & 1 & 1.7 \\
Total & 24 & 40
\end{tabular}

reduced in $21.6 \%(18.3 \%$ below the simple SD and $3.3 \%$ below the double SD).

\section{Speech Evaluation}

Dysfunction of speech was found in 24 of the patients (40\%). Distribution of TFS is shown in Table 3A. Significant relationship of TFS classification to the results of the nonparametric Mayo Test for Apraxia of Oral Movements, the ITPA Auditory Closure subtest, and the Test of Auditory Analysis Skills confirmed the reliability of this categorization (Table 3B). None of the speech test results were found to be dependent on age at testing (TFS, Spearman correlation coefficient $0.01, P>.2$, Mayo, Spearman correlation coefficient $0.05, P>.2$, ITPA, Spearman correlation coefficient $0.2, P>.2$, Test of Auditory Analysis Skills, Spearman correlation coefficient $0.18, P=.17$ ). Speech dysfunction was also found to be related to lower MQ and IQ and to poorer outcomes for acquired abilities and expressive and receptive language (Table 3B).

Test Results in Comparison With Norms for Children Patients were considered either as the whole group or as subgroups comprising patients without or with neurologic damage to evaluate whether neurologic dysfunction might be associated with other developmental dysfunctions. The results of the standardized developmental tests to evaluate MQ, IQ, acquired abilities, and expressive and receptive language are shown in Table 4. Children without neurologic dysfunction did not differ from healthy children in acquired abilities and expressive and receptive language, and they even tended to be better than the control group with respect to MQ and IQ; this, however, could have been due to chance. Children with neurologic dysfunction had significantly poorer than reference performances in all test domains. Patients of the whole group showed lower test results than seen in the control group for all items except IQ.

\section{Discriminatory Power of Neurologic and Speech Functional Scores}

Eighty-one percent of patients with neurologic dysfunction also had speech impairment, whereas 54\% of patients with speech impairment showed simultaneous neurologic dysfunction. By means of both scores, it was possible to discriminate patients with combined dysfunction in the domains of motor, cognitive, and academic abilities from those without dysfunction. In multivariate discrimination analyses, patients with neurologic dysfunction were also found to be impaired in the other domains with a sensitivity of $77 \%$ (percentage of correctly identified patients with impairment) and not impaired with a specificity of $86 \%$ (percentage of correctly identified patients without impairment). Children with speech dysfunction were also found to be impaired in the other domains with a sensitivity of $76 \%$ and not impaired with a specificity of $72 \%$. Patients with neurologic and speech dysfunction or with either one of these could be classified as impaired in motor, cognitive, and academic abilities with sensitivities of $77 \%$ and $78 \%$, respectively, and not impaired with specificities of $83 \%$ and $85 \%$, respectively, indicating that neurologic and speech dysfunctions were strong indicators of global developmental impairment.

\section{Overall Developmental Impairment and Longitudinal Comparison}

Summarizing all examination results, $45 \%$ of the study patients were within the test limits with regard to motor, cognitive, academic, language and speech development, as well as neurologic status, whereas 55\% showed developmental impairment in one or more domains of evaluation, $13.3 \%$ were found to have isolated impairment of speech, and $6.7 \%$ revealed dysfunctions in all domains of child development considered in this study.

Compared with our previous results of the same study group examined at a mean age of 5.4 years, ${ }^{1}$ acquired abilities were now found to be significantly poorer $(P=$ $.02)$, whereas differences in IQ may have been due to chance $(P=.10)$. The rate of neurologic dysfunction significantly increased, from $9.1 \%$ to $26.7 \%(P=.001)$, mainly as a result of additional patients showing motor dyspraxia (fine or gross motor coordination disorder). In total, the proportion of patients without any dysfunction decreased from $74 \%$ to $45 \%$ (Figure 1).

The questionnaires of the 17 patients who did not participate in this study provided percentages of normal and reduced neurodevelopmental outcomes similar to those 
TABLE 3B. Speech outcome after ASO: Relationship of TFS to additional speech and developmental tests

\begin{tabular}{|c|c|c|c|}
\hline & $\begin{array}{l}\text { TFS normal } \\
(n=36)\end{array}$ & $\begin{array}{l}\text { TFS impaired } \\
(\mathrm{n}=24)\end{array}$ & $P$ value* \\
\hline Oral movements, Mayo test & $152.8 \pm 4.5$ & $144.7 \pm 12.4$ & .02 \\
\hline Receptive speech, ITPA Auditory Closure subtest & $26.5 \pm 3.1$ & $22.9 \pm 5.1$ & .006 \\
\hline Receptive speech, Test of Auditory Analysis Skills & $12.1 \pm 1.3$ & $10.2 \pm 2.9$ & .005 \\
\hline MO & $102.5 \pm 18.8$ & $78.2 \pm 31.6$ & .001 \\
\hline 10 & $104.0 \pm 14.0$ & $91.3 \pm 14.0$ & .001 \\
\hline Acquired abilities & $102.1 \pm 15.4$ & $86.1 \pm 14.3$ & .001 \\
\hline Expressive language & $99.7 \pm 12.8$ & $92.0 \pm 10.8$ & .02 \\
\hline Receptive language & $102.3 \pm 10.6$ & $89.2 \pm 11.5$ & $<.001$ \\
\hline
\end{tabular}

Values are mean $\pm S D$, standard deviation.

${ }^{*} P$ values calculated by Mann-Whitney $U$ tests for comparison of normal and impaired TFS.

TABLE 4. Developmental outcomes after ASO compared with norms for healthy children

\begin{tabular}{|c|c|c|c|c|c|}
\hline \multirow[b]{3}{*}{ Developmental test } & \multirow[b]{3}{*}{ Standard score (mean \pm SD) } & \multicolumn{3}{|c|}{ Results (\%) } & \multirow[b]{3}{*}{$P$ valuet } \\
\hline & & \multirow[b]{2}{*}{ Normal* } & \multicolumn{2}{|c|}{ Abnormal } & \\
\hline & & & $<-1$ SD & $<-2$ SD & \\
\hline \multicolumn{6}{|l|}{ MO } \\
\hline All patients ( $n=60$ ) & $92.8 \pm 27.3$ & 73.3 & 11.7 & 15 & .02 \\
\hline Patients without neurologic damage $(n=44)$ & $103.5 \pm 13.6$ & 88.6 & 11.4 & - & .05 \\
\hline Patients with neurologic damage $(n=16)$ & $63.4 \pm 33.7$ & 31.3 & 12.5 & 56.2 & $<.001$ \\
\hline \multicolumn{6}{|l|}{10} \\
\hline All patients $(n=60)$ & $98.9 \pm 16.8$ & 81.7 & 15.0 & 3.3 & .29 \\
\hline Patients without neurologic damage $(n=44)$ & $103.1 \pm 13.7$ & 90.9 & 9.1 & - & .07 \\
\hline Patients with neurologic damage $(n=16)$ & $87.3 \pm 13.3$ & 62.5 & 25.0 & 12.5 & $<.001$ \\
\hline \multicolumn{6}{|l|}{ Acquired abilities } \\
\hline All patients $(n=60)$ & $96.2 \pm 15.2$ & 76.7 & 18.3 & 5.0 & .04 \\
\hline Patients without neurologic damage $(n=44)$ & $99.4 \pm 6.7$ & 81.8 & 15.9 & 2.3 & .40 \\
\hline Patients with neurologic damage $(n=16)$ & $85.3 \pm 12.1$ & 62.5 & 25.0 & 12.5 & $<.001$ \\
\hline \multicolumn{6}{|l|}{ Expressive language } \\
\hline All patients $(n=60)$ & $96.9 \pm 12.6$ & 81.7 & 18.3 & - & .04 \\
\hline Patients without neurologic damage $(n=44)$ & $98.3 \pm 13.0$ & 90.9 & 9.1 & - & .19 \\
\hline Patients with neurologic damage $(n=16)$ & $91.8 \pm 9.7$ & 56.2 & 43.8 & 一 & $<.001$ \\
\hline \multicolumn{6}{|l|}{ Receptive language } \\
\hline All patients $(\mathrm{n}=60)$ & $97.6 \pm 12.5$ & 78.4 & 18.3 & 3.3 & .08 \\
\hline Patients without neurologic damage $(n=44)$ & $100.6 \pm 11.6$ & 88.6 & 9.1 & 2.3 & .36 \\
\hline Patients with neurologic damage $(n=16)$ & $86.5 \pm 9.5$ & 49.9 & 43.8 & 6.3 & $<.001$ \\
\hline
\end{tabular}

*Normal considered to be above $-1 \mathrm{SD}$.

$\dagger P$ values calculated by comparison of mean values, normal and abnormal results relative to age-matched healthy children (standard score $\pm \mathrm{SD}=100 \pm$ $15)$.

among the participants of the study: neurologic dysfunction, $27 \%$; developmental impairment, $40 \%$; and overall proportion of impaired patients, $47 \%$.

Influences of Preoperative, Perioperative, and Postoperative Risk Factors on Neurodevelopmental Outcomes

Comparison of children with and without impairment revealed that severe preoperative acidosis and hypoxia were related to neurologic and speech dysfunctions $(P<.001$ and $P=.001$, respectively, Mann-Whitney $U$ test) and to poorer outcomes with respect to MQ, IQ, acquired abilities, and receptive language $(P=.001, P=.004, P=.02$, and $P=$ .007 , respectively). Duration of $\mathrm{CPB}$ was associated with neurologic and speech dysfunctions $(P=.001$ and $P=$ .003 , respectively) and inversely correlated with MQ (Spearman correlation coefficient $-0.27, P=.04$ ). Perioperative and postoperative cardiocirculatory insufficiency were related to neurologic dysfunction $(P=.02$, MannWhitney $U$ test). Socioeconomic status was also negatively associated with neurologic and speech functions $(P=.02$ and $P=.009$, respectively) and was inversely correlated 


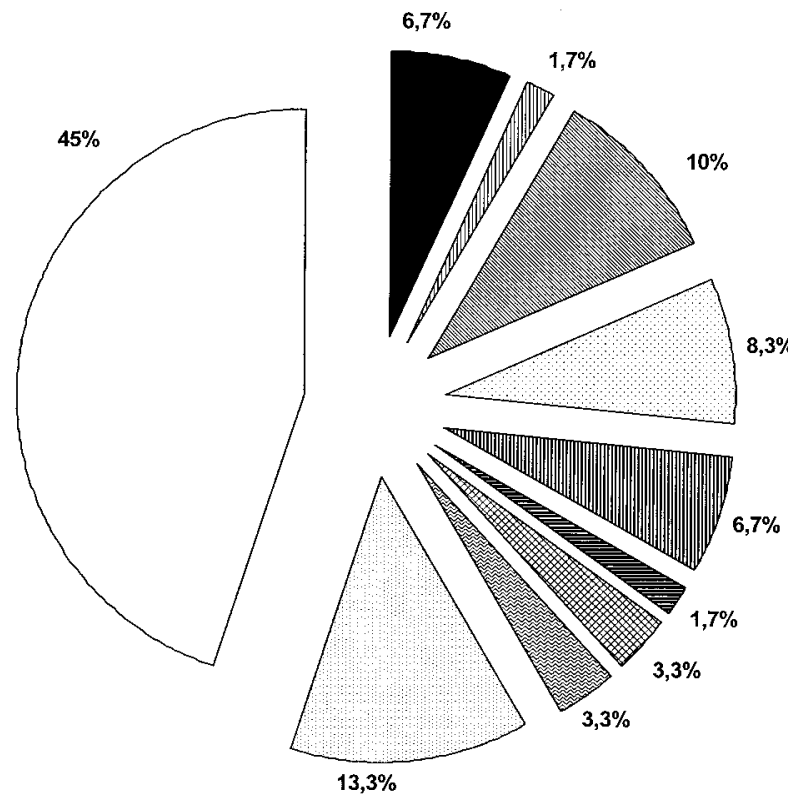

Dysfunction in All Domains

四 Neurology+Motor+

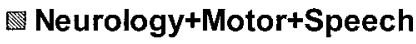

Motor

酳 Neurology+Speech

目 Neurology

Intelligence/Abilities+Speech

图 Intelligence/Abilities

$\square$ Speech

$\square$ No Dysfunction

Figure 1. Diagram illustrating percentages of dysfunction in different domains of assessment as evaluated in 60 patients.

with standard scores of intelligence and acquired abilities (Spearman correlation coefficient $-0.56, P<.001$, and Spearman correlation coefficient $-0.60, P<.001$, respectively), as well as with receptive and expressive language (Spearman correlation coefficient $-0.65, P<.001$, and Spearman correlation coefficient $-0.53, P<.001$, respectively). The additional 11 risk factors (Table 1) were not found to be significantly related to any outcome parameters $(P>.2$ for each).

In the models of multivariable analysis, 7 dependent outcome parameters were considered, each of them related to 8 risk factors as specified previously. Among those, the model was able to confirm 4 variables as independent risk factors with respect to neurodevelopmental outcome. More detailed information is given in Tables 5A and 5B. The presence of severe preoperative acidosis and hypoxia predicted reduced motor function (MQ mean deficit 52.7 points). Duration of CPB was able to predict both neurologic and speech dysfunction (risk elevation 1.8 and 1.9 times, respectively, per 10 minutes of $\mathrm{CPB}$ ). The presence of perioperative and postoperative cardiocirculatory insufficiency predicted neurologic dysfunction (risk elevation 6.5 times) and motor dysfunction (MQ mean deficit 6.8 points). Socioeconomic status was an independent risk factor for reduced IQ, acquired abilities, and expressive and receptive language.

\section{Discussion}

Our data are based on a homogeneous group of neonates with TGA in whom preoperative, perioperative, and post- operative care was conducted according to standardized protocols. Longitudinal follow-up of developmental status 10.5 years after neonatal ASO was prospectively evaluated in a high percentage $(86.5 \%)$ of surviving patients. Of these patients, $77.9 \%$ were examined with an extensive test battery; the remaining $22.1 \%$ were evaluated with a questionnaire. Similar percentages of impairment obtained with both assessment procedures suggest that the neurodevelopmental status of our study group is representative of the outcome of the whole cohort. By means of univariable and multivariable analyses, the outcome data were correlated with retrospectively collected preoperative, perioperative, and postoperative variables.

\section{Neurodevelopmental Outcomes}

Neurologic status. We found marked impairment of clinical neurologic status at age 8 to 14 years after neonatal ASO relative to healthy children and to the results of the same group 5 years ago. ${ }^{1}$ The longitudinal increase of neurologic impairment $(27 \%)$ was due to a higher prevalence of patients with developmental motor coordination disorders, or so-called "soft sign neurology," $8,9,16$ rather than to cerebral palsy or organic motor coordination disorders caused by a central or peripheral neurogenic lesion. These soft neurologic signs could not be detected in the previous study because of the earlier developmental stage of the children. Although neurologic dysfunction was mostly mild, clinical relevance of these findings is underlined by significant correlation with motor, cognitive, academic, and psychosocial impairment (Arch Dis Child, in press) in our 
TABLE 5A. Associations between cerebral risk factors and neurodevelopmental outcomes: Binary outcomes

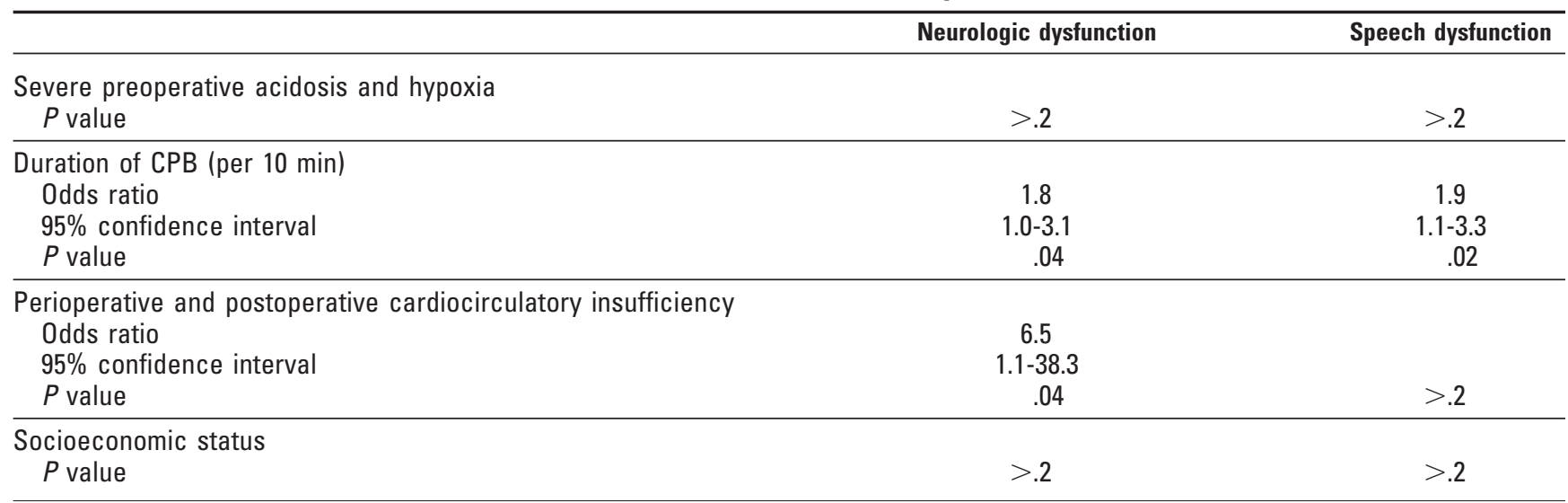

Odds ratios, $95 \%$ confidence intervals, and $P$ values were calculated by a logistic regression for the effects of severe preoperative acidosis and hypoxia, duration of CPB, perioperative and postoperative cardiocirculatory insufficiency, and socioeconomic status (5 categories) with respect to binary outcomes.

TABLE 5B. Associations between cerebral risk factors and neurodevelopmental outcomes: Continuous outcomes

\begin{tabular}{|c|c|c|c|c|c|}
\hline & M0 & 10 & $\begin{array}{l}\text { Acquired } \\
\text { abilities }\end{array}$ & $\begin{array}{l}\text { Expressive } \\
\text { language }\end{array}$ & $\begin{array}{l}\text { Receptive } \\
\text { language }\end{array}$ \\
\hline $\begin{array}{l}\text { Severe preoperative acidosis and hypoxia } \\
\text { Mean deficit } \\
95 \% \text { Confidence interval } \\
P \text { value } \\
\text { Duration of CPB }\end{array}$ & $\begin{array}{c}52.7 \\
35.4 \text { to } 69.9 \\
<.001\end{array}$ & $\begin{array}{l}17.3 \\
5.8 \text { to } 28.8 \\
.12\end{array}$ & $\begin{array}{l}17.2 \\
0.2 \text { to } 34.1 \\
>.2\end{array}$ & $\begin{array}{l}\quad 8.9 \\
-4.1 \text { to } 21.8 \\
>.2\end{array}$ & $\begin{array}{l}14.6 \\
2.1 \text { to } 27.2 \\
>.2\end{array}$ \\
\hline $\begin{array}{l}R^{2} \\
P \text { value }\end{array}$ & $\begin{array}{c}0.52 \\
>.2\end{array}$ & $\begin{array}{c}0.42 \\
>.2\end{array}$ & $\begin{array}{c}0.41 \\
>.2\end{array}$ & $\begin{array}{c}0.35 \\
>.2\end{array}$ & $\begin{array}{c}0.50 \\
>.2\end{array}$ \\
\hline $\begin{array}{l}\text { Perioperative and postoperative cardiocirculatory insufficiency } \\
\text { Mean deficit } \\
95 \% \text { Confidence interval } \\
P \text { value }\end{array}$ & $\begin{array}{l}6.8 \\
-14.9 \text { to } 28.6 \\
.03\end{array}$ & $\begin{array}{l}7.7 \\
-4.9 \text { to } 20.2 \\
>.2\end{array}$ & $\begin{array}{l}3.3 \\
-9.8 \text { to } 16.3 \\
>.2\end{array}$ & $\begin{array}{l}\quad 4.5 \\
-6.8 \text { to } 15.9 \\
>.2\end{array}$ & $\begin{array}{c}2.8 \\
-8.4 \text { to } 13.9 \\
>.2\end{array}$ \\
\hline $\begin{array}{l}\text { Socioeconomic status } \\
\quad R^{2} \\
P \text { value }\end{array}$ & $\begin{array}{c}0.52 \\
>.2\end{array}$ & $\begin{array}{c}0.42 \\
.001\end{array}$ & $\begin{array}{l}0.41 \\
<.001\end{array}$ & $\begin{array}{c}0.35 \\
.007\end{array}$ & $\begin{array}{l}0.50 \\
<.001\end{array}$ \\
\hline
\end{tabular}

Mean deficits, $95 \%$ confidence intervals, and $P$ values were calculated by a generalized linear model for the effects of severe preoperative acidosis and hypoxia and of perioperative and postoperative cardiocirculatory insufficiency with respect to continuous outcomes. $R^{2}$ and $P$ values were calculated by a generalized linear model for the effects of duration of CPB and socioeconomic status with respect to continuous outcomes.

study group. Our incidence of neurologic impairment was in a range similar to rates reported in other studies for definite neurologic abnormalities among children after neonatal ASO, ${ }^{3,17}$ although it was markedly higher than in cohorts operated on later, in 1994 to $1995 .^{2,4}$ This may at least in part be due to improved preoperative management, which has been found to exert a significant influence on neurodevelopmental outcome. It must be noted, however, that the children operated later on were younger at examination.

Motor function. Gross motor dysfunction, as judged on the basis of a standardized assessment (MQ), was found to be more prevalent among our patients $(27 \%)$ than in the general population. This figure is comparable to the frequency of gross motor impairment in our cohort at the age of 5.4 years and to the results in the Boston study at the age of 4 years. ${ }^{3}$ The presence of gross motor dysfunction according to MQ showed a high overlap with neurologic abnormalities.

Intelligence. Formal intelligence, as based on IQ assessment, was not reduced relative to healthy children. This finding is consistent with the previous results of our study group $^{1}$ and with the results of our recent cohort of younger children, ${ }^{2}$ whereas intelligence considerably below population norms after neonatal ASO has been demonstrated in other reports. ${ }^{3,4,17}$

Academic achievement. By means of formal testing of acquired abilities, we demonstrated (consistent with another report after neonatal $\mathrm{ASO}^{17}$ ) significantly reduced outcomes 
in age-adapted learning and knowledge relative to the test norms and to the results of the same cohort 5 years ago.

Language and speech. Expressive and receptive language were found to be poorer than population norms among our patients. Speech outcome assessed by the TFS, comprising oral nonspeech functions as well as expressive speech functions (articulation, phonation and coordination), was markedly reduced relative to healthy children. ${ }^{18}$ Normal auditory test results demonstrated that this finding could not be attributed to hearing deficits. Rather, general motor dysfunction was present in $40 \%$ of the speech-impaired children. In addition, disabilities of central integration appeared to contribute to our high rate of speech dysfunction (40\% of the cohort), as suggested by strong correlations of TFS with performance in tests of receptive speech and language. This is underlined by the prevalence of a quite high rate of children with isolated speech impairment (13\% of the cohort) without neurologic disorder, in contrast to a minority of children with neurologic disorder who did not have accompanying speech impairment (5\% of the cohort). A high prevalence of speech and language dysfunction was also demonstrated in the Boston cohort. ${ }^{3}$ In that study as well as in ours, these dysfunctions were strongly associated with motor, cognitive, and academic disabilities, as well as with behavioral and social problems. Therefore speech and language dysfunctions are an important indicator of global developmental impairment. ${ }^{19-21}$

Overall impairment. According to the data discussed previously, the increase in detection rate of developmental impairment in one or more domains of assessment (55\% vs $26 \% 5$ years ago) is due mainly to the high incidence of neurologic and speech and language disorders, which are more easily detected in older than in younger children.

\section{Risk Factors for Neurodevelopmental Outcomes}

The factors influencing neurodevelopmental outcome after neonatal cardiac surgery are complex, involving the interactions of preoperative, perioperative, and postoperative parameters. ${ }^{22,23}$ The independent risk factors for neurodevelopmental dysfunction found in this study are discussed here.

Socioeconomic status. In our study group, which represented an even level of socioeconomic status relative to the German population, ${ }^{5}$ low socioeconomic status predicted poorer outcome in all cognition-related domains of evaluation as intelligence, academic achievement, and language. This is consistent with similar associations observed in other studies. ${ }^{3,17}$ The fact that academic achievement and language in the group as a whole were below expected population norms, however, suggests influences of additional factors.

Preoperative factors. The structural and functional immaturity of the cerebral circulation predisposes the neonate toward acquired cerebrovascular lesions, such as intracra- nial hemorrhage and hypoxic-ischemic injury. ${ }^{22}$ In addition to the well-known general risk of low arterial oxygen saturation in children with cyanotic heart lesions such as TGA, situations of particularly severe preoperative hypoxia, such as were documented in some of our patients before surgery, have a negative impact on later speech and motor functions. Children with TGA represent a group without prevalent risk of genetic abnormality with respect to morbidity of the central nervous system ${ }^{24}$ and therefore appear particularly appropriate for investigation of preoperative influences on developmental sequelae after neonatal cardiac surgery. The high incidence of neurobehavioral abnormalities in neonates documented before cardiac surgery and persisting in most after surgery ${ }^{25}$ underlines the importance of preoperative brain injury for later developmental outcome. In our study, the outcome of motor development was primarily predicted by severe preoperative acidosis and hypoxia.

Perioperative and postoperative factors. Although acute manifestations of neurologic injury in the early postoperative period are often transient, they may be predictive of increased long-term neurodevelopmental dysfunction. ${ }^{26}$ The risk for brain injury comprises disturbances in postCPB cerebral perfusion, intrinsic vasoregulation, and cardiocirculatory function. ${ }^{23}$ In our study, cardiocirculatory insufficiency, defined as low cardiac output situations resistant to intensive care treatment in the early postoperative period, was found to be an independent risk factor for later neurologic and motor disorders. Postoperative clinical seizures, evident in as many as $15 \%$ of neonates after cardiac surgery, ${ }^{27,28}$ have been found to be associated with reduced developmental impairment after ASO.3,29 In our study group, however, no correlation could be detected between the occurrence of clinically detected seizures and later development. This is consistent with our previous results on the same study group at age 5.4 years $^{1}$ as well as on our younger cohort ${ }^{2}$ and may be due at least in part to the low incidence of clinical postpump seizures in our patients, among whom postoperative electroencephalography was not routinely performed.

Low-flow cardiopulmonary bypass. The technique of vital organ support during cardiac surgery in our institution includes a combination of low-flow CPB and DHCA. The risks of low-flow CPB comprise the exposure to cerebral embolic injury, cerebral hypoperfusion, and global inflammatory response continuing into the postoperative period. ${ }^{30-32}$ In this study, longer duration of CPB was detected as an independent risk factor for poorer outcomes in neurologic and speech functions at age 10.5 years after ASO, whereas it had marginally increased the risk of intellectual impairment at the age of 5.4 years. ${ }^{1}$ A recent report on the possibly deleterious effects of CPB on intelligence of patients after surgical closure of atrial septal defect versus those after interventional closure (device implantation) un- 
derlines the necessity of a critical attitude with respect to current CPB strategies. ${ }^{33}$

Children who needed additional patch closure of a ventricular septal defect, usually associated with longer support times, have been found to be at increased risk for poorer developmental outcomes. 3,34 We could not confirm this observation, probably because of the small number of patients with that constellation.

Deep hypothermic cardiocirculatory arrest. DHCA leads to prolonged complete cerebral ischemia, including impairment of cerebral metabolism and vascular autoregulation. ${ }^{22,35}$ Predominant exposure to DHCA, as opposed to predominant use of low-flow $\mathrm{CPB}$, was associated with worse outcomes in motor and speech development at the age of 4 years after neonatal $\mathrm{ASO},{ }^{3}$ whereas the institution of cardiac arrest and its duration did not affect neurologic and cognitive outcomes in a group of preschool-aged children after infant heart surgery. ${ }^{4}$ In this study, multivariable analysis did not point to DHCA duration, although longer than usual, as an independent risk factor for adverse neurodevelopmental outcome, consistent with our previous findings. ${ }^{1,2}$ This underlines results from animal studies, in which neurologic impairment did not occur until circulatory arrest times exceeded 60 minutes. ${ }^{36}$

Other aspects of intraoperative management. Adequate degree and duration of the cooling period are important to reach the profoundly hypothermic brain temperatures that lead to sufficient reduction of cerebral metabolism. ${ }^{37}$ Toorapid cooling may exert adverse effects on cognitive functions. ${ }^{38}$ Although duration of cooling on CPB in our patients was shorter than recommended, this factor did not have a negative impact on developmental outcome.

There is evidence that cerebral hyperthermia of $2^{\circ} \mathrm{C}$ or $3^{\circ} \mathrm{C}$ above core temperatures in children after $\mathrm{CPB}$, as measured by jugular venous bulb temperature, typically occurs in the perioperative period after termination of $\mathrm{CPB}$, inducing the risk of neurologic sequelae caused by hypoxicischemic lesions. ${ }^{36,39,40}$ Conflicting evidence exists concerning the $\mathrm{pH}$ management during $\mathrm{CPB}$. Whereas the $\mathrm{pH}$-stat strategy was found preferable in the postoperative period, ${ }^{22,41,42}$ use of the alpha-stat versus the $\mathrm{pH}$-stat acid-base strategy during reparative infant cardiac surgery was not related to either improved or impaired neurodevelopmental outcomes 1 year after surgery. ${ }^{43}$ Experimental data recently proved $\mathrm{pH}$-stat $\mathrm{CPB}$ management in combination with DHCA to be superior to alpha-stat CPB with respect to neurologic outcome. ${ }^{44}$ In our institution, the $\mathrm{pH}$-stat method was always used.

\section{Limitations}

In this study the number of patients for multivariable analysis was somewhat limited. Therefore statistical power to identify predictors of developmental delay was limited to those with high associations.

\section{Conclusions}

Our study points out that developmental impairment 10 years after neonatal ASO with combined DHCA and lowflow $\mathrm{CPB}$, as performed in our institution, was more prevalent than in both the general population and the same study group at the age of 5 years. Reduced cognitive function according to formal intelligence testing, however, was not observed.

In our experience, the risk of long-term neurodevelopmental impairment after neonatal corrective cardiac surgery is related to the deleterious effects of the global perioperative management and to special adverse effects of prolonged CPB duration. Severe preoperative acidosis and hypoxia and postoperative hemodynamic instability must be considered as important additional risk factors.

We thank DiplPsych M. Braunschweig, Education Advice Center Aachen, Germany, for her advice concerning developmental testing.

\section{References}

1. Hövels-Gürich HH, Seghaye MC, Däbritz S, Messmer BJ, von Bernuth $\mathrm{G}$. Cognitive and motor development in preschool and schoolaged children after neonatal arterial switch operation. J Thorac Cardiovasc Surg. 1997;114:578-85.

2. Hövels-Gürich HH, Seghaye MC, Sigler M, Kotlarek F, Bartl A Neuser J, et al. Neurodevelopmental outcome related to cerebral risk factors in children after neonatal arterial switch operation. Ann Thorac Surg. 2001;71:881-8.

3. Bellinger DC, Wypij D, Kuban KC, Rappaport LA, Hickey PR, Wernovsky G, et al. Developmental and neurological status of children at 4 years of age after heart surgery with hypothermic circulatory arrest or low-flow cardiopulmonary bypass. Circulation. 1999;100: 526-32.

4. Sharma R, Choudhary SK, Mohan MR, Padma MV, Jain S, Bhardwaj $\mathrm{M}$, et al. Neurological evaluation and intelligence testing in the child with operated congenital heart disease. Ann Thorac Surg. 2000;70: 575-81.

5. Moore H, Kleining G. Das soziale Selbstbild der Gesellschaftsschichten in Deutschland. Kölner Z Soziologie Sozialpsychologie. 1968;20: 86-119.

6. Sigler M, Vazquez-Jimenez JF, Grabitz RG, Hövels-Gürich HH, Messmer BJ, von Bernuth G, et al. Time course of cranial ultrasound abnormalities after arterial switch operation in neonates. Ann Thorac Surg. 2001;71:877-80.

7. Paine RS, Oppé TE. Die neurologische Untersuchung von Kindern. Stuttgart, Germany: Georg Thieme Verlag; 1970.

8. Dewey D, Kaplan BJ. Subtyping of developmental motor deficits. Dev Neuropsychol. 1994;10:265-84.

9. Michaelis R. Guidelines of the Society for Neuropediatrics: motor coordination and perception disorders. Society for Neuropediatrics. Working group of the Scientific Medical Societies, awmf@uni-duesseldorf.de, Germany, 1999.

10. Kiphard EJ, Schilling F. Körper-Koordinationstest für Kinder. Weinheim-Basel, Germany: Beltz-Verlag; 1974.

11. Kaufman AS, Kaufman NL. Kaufman assessment battery for children (K-ABC). German version: Melchers U, Preuß U. Kaufman-Testbattene für Kindes. 2nd ed. Lisse, The Netherlands: Swets \& Zeitlinger; 1994

12. Robbins J, Klee T. Clinical assessment of oropharyngeal motor development in young children. J Speech Hear Disord. 1987;52:271-7.

13. Darley FL, Aronson AE. Motor speech disorders. Boston: Little Brown; 1975.

14. Kirk SA, McCarthy JJ, Kirk WD. Illinois test of psycholinguistic abilities (revised). Urbana (IL): University of Illinois Press; 1968. 
German version: Angermaier M. Psycholinguistischer Entwicklungstest. Weinheim, Germany: Beltz-Test; 1974.

15. Rosner J. Screening for perceptual skills dysfunction: an up-date. JAm Optom Assoc. 1979;50:1115-9.

16. Piek JP, Coleman-Carman R. Kinaesthetic sensitivity and motor performance of children with developmental co-ordination disorder. Dev Med Child Neurol. 1995;37:976-84.

17. Ellerbeck KA, Smith ML, Holden EW, McMenamin SC, Badawi MA, Brenner JI, et al. Neurodevelopmental outcomes in children surviving d-transposition of the great arteries. J Dev Behav Pediatr. 1998;19: $335-41$.

18. Dodd B. Differential diagnosis and treatment of children with speech disorder. London: Whurr Publishers; 1995.

19. Beitchman JH, Wilson B, Brownlie EB, Walters H, Lancee W. Longterm consistency in speech/language profiles: I. Developmental and academic outcomes. J Am Acad Child Adolesc Psychiatry. 1996;35: 804-14.

20. Beitchman JH, Wilson B, Brownlie EB, Walters H, Inglis A, Lancee W. Long-term consistency in speech/language profiles: II. Behavioral, emotional, and social outcomes. J Am Acad Child Adolesc Psychiatry. 1996;35:815-25.

21. Beitchman JH, Wilson B, Johnson CJ, Atkinson L, Young A, Adlaf E, et al. Fourteen-year follow-up of speech/language-impaired and control children: psychiatric outcome. J Am Acad Child Adolesc Psychiatry. 2001:40:75-82.

22. du Plessis AJ. Neurologic complications of cardiac disease in the newborn. Clin Perinatol. 1997;24:807-26.

23. du Plessis AJ. Mechanisms of brain injury during infant cardiac surgery. Semin Pediatr Neurol. 1999;6:32-47.

24. Goldmuntz E, Clark BJ, Mitchell LE, Jawad AF, Cuneo BF, Reed L, et al. Frequency of $22 \mathrm{q} 11$ deletions in patients with conotruncal defects. J Am Coll Cardiol. 1998;32:492-8.

25. Limperopoulos C, Majnemer A, Shevell MI, Rosenblatt B, Rohlicek C, Tchervenkov C. Neurodevelopmental status of newborns and infants with congenital heart defects before and after open heart surgery. J Pediatr. 2000;137:638-45.

26. Ferry PC. Neurologic sequelae of open-heart surgery in children: an 'irritating question.' Am J Dis Child. 1990;144:369-73.

27. Newburger JW, Jonas RA, Wernovsky G, Wypij D, Hickey PR, Kuban KC, et al. A comparison of the perioperative neurologic effects of hypothermic circulatory arrest versus low-flow cardiopulmonary bypass in infant heart surgery. N Engl J Med. 1993;329:1057-64.

28. Miller G, Eggli KD, Contant C, Baylen BG, Myers JL. Postoperative neurologic complications after open heart surgery on young infants. Arch Pediatr Adolesc Med. 1995;149:764-8.

29. Rappaport LA, Wypij D, Bellinger DC, Helmers SL, Holmes GL, Barnes PD, et al. Relation of seizures after cardiac surgery in early infancy to neurodevelopmental outcome. Boston Circulatory Arrest Study Group. Circulation. 1998;97:773-9.
30. Jonas RA. Neurological protection during cardiopulmonary bypass/ deep hypothermia. Pediatr Cardiol. 1998;19:321-30.

31. Kirkham FJ. Recognition and prevention of neurological complications in pediatric cardiac surgery. Pediatr Cardiol. 1998;19:331-45.

32. Taylor KM. Central nervous system effects of cardiopulmonary bypass. Ann Thorac Surg. 1998;66(5 Suppl):S20-4.

33. Visconti KJ, Bichell DP, Jonas RA, Newburger JW, Bellinger DC. Developmental outcome after surgical versus interventional closure of secundum atrial septal defect in children. Circulation. 1999;100(19 Suppl):II145-50.

34. Bellinger DC, Jonas RA, Rappaport LA, Wypij D, Wernovsky G, Kuban KC, et al. Developmental and neurologic status of children after heart surgery with hypothermic circulatory arrest or low-flow cardiopulmonary bypass. $N$ Engl J Med. 1995;332:549-55.

35. Pua HL, Bissonnette B. Cerebral physiology in paediatric cardiopulmonary bypass. Can J Anaesth. 1998;45:960-78.

36. Kurth CD, Steven JM. Keeping a cool head. Anesthesiology. 2000; 93:598-600.

37. Kern FH, Ungerleider RM, Schulman SR, Meliones JN, Schell RM, Baldwin B, et al. Comparing two strategies of cardiopulmonary bypass cooling on jugular venous oxygen saturation in neonates and infants. Ann Thorac Surg. 1995;60:1198-202.

38. Bellinger DC, Wernovsky G, Rappaport LA, Mayer JE Jr, Castaneda AR, Farrell DM, et al. Cognitive development of children following early repair of transposition of the great arteries using deep hypothermic circulatory arrest. Pediatrics. 1991;87:701-7.

39. Shum-Tim D, Nagashima M, Shinoka T, Bucerius J, Nollert G, Lidov HG, et al. Postischemic hyperthermia exacerbates neurologic injury after deep hypothermic circulatory arrest. J Thorac Cardiovasc Surg. 1998;116:780-92.

40. Bissonnette B, Holtby HM, Davis AJ, Pua H, Gilder FJ, Black M. Cerebral hyperthermia in children after cardiopulmonary bypass. Anesthesiology. 2000;93:611-8.

41. du Plessis AJ, Johnston MV. The pursuit of effective neuroprotection during infant cardiac surgery. Semin Pediatr Neurol. 1999;6:55-63.

42. Kurth CD, O'Rourke MM, O'Hara IB. Comparison of pH-stat and alpha-stat cardiopulmonary bypass on cerebral oxygenation and blood flow in relation to hypothermic circulatory arrest in piglets. Anesthesiology. 1998;89:110-8.

43. Bellinger DC, Wypij D, du Plessis AJ, Rappaport LA, Riviello J, Jonas RA, et al. Developmental and neurologic effects of alpha-stat versus $\mathrm{pH}$-stat strategies for deep hypothermic cardiopulmonary bypass in infants. J Thorac Cardiovasc Surg. 2001;121:374-83.

44. Priestley MA, Golden JA, O'Hara IB, McCann J, Kurth CD. Comparison of neurologic outcome after deep hypothermic circulatory arrest with alpha-stat and $\mathrm{pH}$-stat cardiopulmonary bypass in newborn pigs. J Thorac Cardiovasc Surg. 2001;121:336-43. 